\title{
Immunological and Hematological Response to Local Transplantation of Stem Cells in Injured Radial Nerve of Dogs
}

\author{
Haidar H. Essa ${ }^{1 *}$, Huda S. Jasim ${ }^{2}$, Hameed A. Kadhim ${ }^{3}$ \\ ${ }^{I}$ Department of Microbiology, College of Veterinary Medicine, University of Baghdad, Iraq \\ ${ }^{2}$ Department of Surgery, College of Veterinary Medicine, University of Baghdad, Iraq
}

\begin{abstract}
The current study was carried out to investigate the immunological and hematological changes due to local transplantation of human umbilical cord-mesenchymal-stem cells (HUC-MSCs) and scaffold-stem cells (SSCs) into the injured radial nerve. Therefore, three equal groups of dogs were subjected to this study; experimental (EG), positive control (PCG) and negative control (NCG). At $1^{\text {st }}$ week, dogs of EG were showed an obvious mobility dysfunction. At $2^{\text {nd }}$ and $4^{\text {th }}$ weeks, there were apparent improvements reported on general and physical activities as well as functional ability of forelimb with the presence of slight lameness that was cured completely at $5^{\text {th }}$ week. Regarding to immunobiomarkers, insignificant differences were showed at $1^{\text {st }}$ week. However, significantly increase in IgG and TNF- $\alpha$, and decrease in IL-10 was reported at $2^{\text {nd }}, 4^{\text {th }}$, and $6^{\text {th }}$ weeks. Regarding to hematologic parameters, significantly increases were recorded in total WBCs from $2^{\text {nd }}$ week onwards, lymphocytes and neutrophils at $2^{\text {nd }}$ week, monocytes at the $2^{\text {nd }}$ and $4^{\text {th }}$ weeks, and total RBCs at the $8^{\text {th }}$ and $16^{\text {th }}$ weeks. Significant differences were not reported in values of PCV and $\mathrm{Hb}$ throughout this study. In conclusion, HUC-MSCs and SSCs confirmed high activities in supporting of immunological and hematological responses, and in restoration of nerve function.
\end{abstract}

\section{Keywords: Immune response, Stem cells, Transplantation, Dogs, Iraq.}

\section{Introduction}

Peripheral motor nerve injuries (NIs) are the most common cases that occur due to systemic diseases such as autoimmune diseases (1), and diabetes (2); or localized damage such as trauma (3), tumors (4), and compression (5). In addition, NIs can occur as separate neurological conditions or more commonly in association with soft tissue, vascular, and/or skeletal damage resulting in sensory deficits, loss of motor function, or a combination of both $(6,7)$. Enervated muscle atrophy is still a major problem in the field of peripheral NI repair.

Functional recovery is of utmost importance for limb rescue in the management of peripheral NIs

\footnotetext{
*Correspondence: haidarhussein03@gmail.com

Department of Microbiology, College of Veterinary Medicine, University of Baghdad, Baghdad, Iraq. Received: 29 April 2020, Accepted: 7 July 2020, Published: 28 December 2020.
}

This article is an open access article under the terms and conditions of the Creative Commons Attribution License (CC BY 04 https://crerativecommons.org/licenses/by/4.0). that range from compression to complete nerve transection with no continuity of any neural structure (8). The inflammatory response to the injury affects tissue regeneration and has become an important factor influencing the prognosis of patients. Therefore, it is very important to develop strategies that can utilize the beneficial aspects of the immune response and at the same time limit the potential deleterious aspects (9). The majority of peripheral nerve injured patients complain of persistent and severe pain, motor dysfunction, and prolonged disability.

Though, there was an advance in types of perineural and epineural suture to stitch free-nerve ends, the outcomes are still generally suboptimal for the existing of alternative approaches to support treatment (10). Cell therapy using stem cells (SCs) emerged as a promising source of hope in the regenerative medicine to overcome the difficulties in the repairing, replacing, and regenerating of damaged organ/tissue due to injuries and/ or diseases (11). One of the most important issues is the requirement to evaluate how much SCs are needed to regenerate damaged 
tissues, and what the form must be provided to complete the demand (12). After recruiting of progenitor cells and endogenous SCs to build of new tissues in responding to environmental stimuli, many clues could be drawn from regenerative and developmental biology (13). One way to enhance nerve regeneration is by using adult mesenchymal SCs (MSCs) which have the potential to self-renew and differentiate into several lineages including neuronal cell types such as Schwann cells $(\mathbf{1 4}, \mathbf{1 5})$. Capability to control and tailor tissue formation suggested that tissue engineering has the ability to provide new alternative preferences in the field of regenerative medicine. This will result in new insights into how tissue regenerates, offering to impact approaches with which they are promoting for tissue repairing without any defect $(\mathbf{1 2}, \mathbf{1 6})$. Since there is not much known about the effects of the chemical composition of SSCs in regeneration of PN injury, this study was aimed to determine whether HUCMSCs and SSCs can improve limb functional recovery of radial nerve (RN) injury, as well as evaluation changes in some immune markers and main blood parameters during the healing period.

\section{Materials and Methods}

\section{Ethical approval}

This study was licensed and performed under the regulation of the Department of Microbiology, and Department of Surgery and obstetrics in the College of Veterinary Medicine/ University of Baghdad, Baghdad, Iraq. The steps of HUC collection, proliferation, and scaffold stem cells preparation were approved by the Scientific and Ethical Committee of Baghdad University.

\section{Experimental animals}

Eighteen local breed male dogs (aged 12-18 months weighing $8-10 \mathrm{Kg}$ ) were selected for this study. Prior to the surgery, the dogs were clinically examined to detect any diseases, treated against external and internal parasites, and acclimated to the new environment for minimum of 30 days prior to surgery, with providing good environmental and management hygienic conditions.

\section{Experimental design}

The animals were divided into 3 equal groups
(6 dogs in each one) in solitary cages as following:

1. Experimental group $(E G)$ : In which, the radial nerve (RN) has been transected at zero time (the first day) of the experimentally period, and treated locally with both human umbilical cord-mesenchymal stem cells (HUC-MSCs) and scaffold stem cells (SSCs). Then, the transected nerve was taped, and then, the muscles and coetaneous surgical incision were sutured.

2. Positive Control group (PCG): In which, RN was transected, but not treated with HUCMSCs and SSCs.

3. Negative Control group $(N C G)$ : Animals of this group were not subjected to surgery; hence, RN neither dissected nor treated with HUC-MSCs and SSCs.

Experimental period of this study was lasted for 16 weeks (from October-2018 to May-2019); during which, all dogs were feed and allowed to free-drink from the same source, and received high management care.

\section{Preparation of HUC-MSCs and SSCs}

Following sterile conditions, fresh HUC was obtained immediately from a healthy delivering woman after giving birth, cold transported directly to the laboratory, and processed according to the method described previously by Xue et al. (2011), (17).

Briefly, HUC was cut into approximately $1.5 \mathrm{~cm}$ pieces, the gelatinous tissue surrounding the vessels was excised and minced into $1 \mathrm{~mm}^{3}$, and then plated in-closed cell culture flasks. After 20 days, the adhered spindle-shaped cells were collected and re-cultured again for several passages. The proliferated HUC-MSCs were divided into two parts; one used for additional proliferation of SCs, and the other part was used for the preparation of lyophilized scaffold stem cells (SSCs) according to the method described previously by Dan et al. (2017), (18). Both HUCMSCs and SSCs, were kept in refrigerator under a temperature of $2-8^{\circ} \mathrm{C}$ until they used for the treatment of RN injury surgical procedure of $\mathrm{RN}$ injury and SCs therapy. In a highly aseptic conditions, the dogs of the $E G$ and $P C G$ were anesthetized and subjected to surgical transection of $\mathrm{RN}$ to make a gap of approximately $1 \mathrm{~cm}$ 
between the ends of the nerve. In dogs of EG, the gap between the ends of the transected $\mathrm{RN}$ was tubilized by a submucosal epithelial layer derived from bovine urinary bladder, and filled by small pieces of HUC-MSCs and SSCs; whereas, the gap between the ends of RN of $P C G \operatorname{dogs}$ was left without treatment. Finally, the surgical wounds of all $E G$ and $P C G$ were sutured and bandaged aseptically, and then, the dogs were subjected to post-operative care.

\section{Clinical examination}

To detect therapeutic effects of both HUC-MSCs and SSCs, clinical examination including general and physical evaluation of the activities and mobility function were performed weekly throughout the experimental period, for all experimental groups.

\section{Hematological examination}

During the experimental period within one-week interval, $3 \mathrm{ml}$ of cephalic venous blood was sampled from each animal of all groups into an EDTA-glass tube under aseptic conditions. White blood cells (WBCs) parameters [total WBCs count, lymphocytes, neutrophils, and monocytes], and red blood corpuscles (RBCs) parameters [total RBCs, packed cell volume (PCV), and hemoglobin $(\mathrm{Hb})$ ] were measured immediately using the automated Mythic18 Vet blood analyzer (Orphee', Switzerland). Then, the tubes were centrifuged at $3000 \mathrm{rpm}$ for $5 \mathrm{~min}$ for obtaining the sera that kept frozen in labeled Eppendorf tubes at $-4^{\circ} \mathrm{C}$ until be used for the measuring of immunological parameters (19).

\section{Immunological examination}

In this study, canine immunoglobulin ( $\mathrm{IgG}$ ), interleukin-10 (IL-10), and tumor necrosis factor$\alpha$ (TNF- $\alpha$ ) were measured in plasma samples using of specific Sandwich ELISA kits (Sunlong Biotech, China). According to the manufacturer's instruction, the Standards were diluted serially and Dilution Buffer was prepared. At terminal stage of the assay, optical density was read at $450 \mathrm{~nm}$. Finally, the concentrations of immune biomarkers (IgG, IL-10, and TNF- $\alpha$ ) were calculated by the $\log$ scale ( $X$-axis and $Y$-axis) and multiplying by the dilution buffer.

\section{Statistical analysis}

All collected study data was arranged using the Microsoft Office Excel (version ${ }^{2007}$ ), and analyzed by the computerized IBM-SPSS (version 16) programs. One-Way ANOVA and Duncan test were used for statistical evaluation of hematological and immunological values between the three experimental groups (20). Statistical differences were considered significant at $\mathrm{P} \leq 0.05$.

\section{Results and Discussion}

Prior to the surgical procedure of RNI, the results of clinical examination among the dogs of all experimental groups were revealed on normal general and physical activities. Post-surgery, at the $1^{\text {st }}$ week of the experiment, the dogs of $E G$ and $P C G$ were showed a significant movement dysfunction with apparent decline in appetite, changes in sleeping habits, slight increase in temperature, shallow and rapid breathing, and slight tachycardia. During the $2^{\text {nd }}$ and $4^{\text {th }}$ weeks, apparent improvement in general and physical activities with the ability of the dogs to extend their forelimb and standup normally were seen, but a slight degree of lameness was observed. Whilst, the dogs of $P C G$ showed more observable defects when these animals extend their forelimbs, and tried to stand-up. At the pre-final week, the dogs of $E G$ showed normal general and physical activities with full absence of symptoms of forelimb muscle atrophy and lameness; and the ability of the dogs to extend their forelimbs normally without any movement dysfunction. In $P C G$, obvious symptoms of lameness, muscle atrophy, and movement dysfunction were showed on the dogs which continued until the final week $\left(16^{\text {th }}\right.$ week). Based on these findings, we confirmed that there was complete healing for the injured radial nerves and sutured muscles with restoring of normal movement function and absence of the symptoms of the defects in extending the limbs. One of the focuses for generating new bio-materials in regenerative medicine is the development of multifunctional extracellular matrix that can mimic a natural environment for cells (21). To do so, many natural and synthetic materials were derived and applied in various tissues engineering applications to support cell culture (22-25). 
Human placenta is one of the natural materials, which generates a matrix compromising several growth factors that has the role of angiogenesis (26). Previously, it was hypothesized that nerve tissues lack the capability of regenerating; however, McKay (1997) confirmed that SCs can differentiate to numerous cell types such as neurons and the ability to self-renew, providing a vital abundance source for neurons (27).Also, Yan et al. (2004) showed that the transplanted SCs grew into a bridge grafting, and there are many myelin basic protein-positive cells, indicating the role of transplanted SCs in the formation of medullary sheath (28). However, we suggested that both HUC-MSCs and SSCs can survive and differentiate into motor neurons after being transplanted into damaged injured radial nerve. Also, the transplanted SCs had played a role in delaying muscle atrophy before the connection between differentiated neurons and denervated muscles was established. Regarding the levels of IgG, no significant variation $(\mathrm{P} \leq 0.05)$ was detected between the findings of the three experimental groups; $E G, P C G$, and $N C G$ at the $1^{\text {st }}$ week. However, significant increases $(\mathrm{P} \leq 0.05)$ in the values of $E G$ were detected at the $2^{\text {nd }}, 4^{\text {th }}$, and $6^{\text {th }}$ weeks comparing with the values of $N C G$, and significant reduction $(\mathrm{P} \leq 0.05)$ from the $4^{\text {th }}$ week onward until the last week ( $16^{\text {th }}$ week) when compared to the $P C G$. Among the results of $E G$, the highest significant increases $(\mathrm{P} \leq 0.05)$ in values of $\operatorname{IgG}$ were detected in the $2^{\text {nd }}$ week (Figure 1).

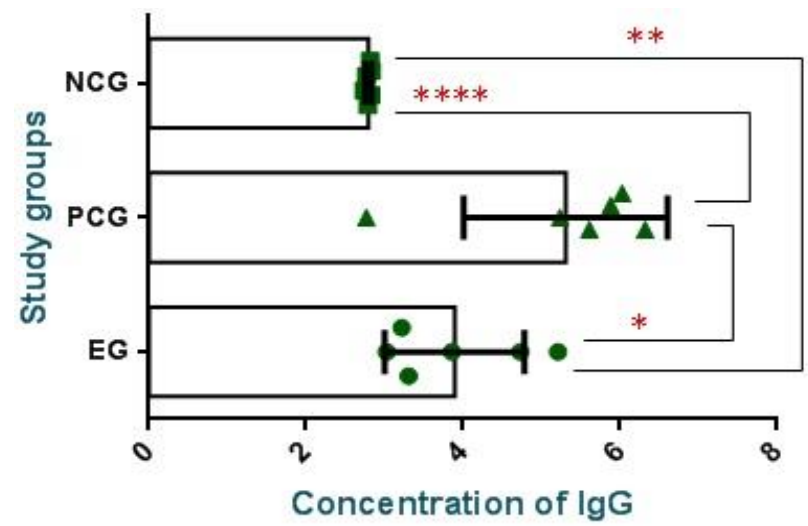

Figure 1. Figure (1): Total values of IgG among the study groups and the time points. $(*),(* *)$, and $(* * * *)$ referred to significant differences between groups as $\mathrm{P} \leq 0.05, \mathrm{P} \leq 0.01$ and $\mathrm{P}<0.0001$ respectively.

For IL-10, there was insignificant variation $(\mathrm{P} \leq 0.05)$ detected between the values of the three experimental groups; $E G, P C G$, and $N C G$; at the $1^{\text {st }}$ week. However, significant decreases $(\mathrm{P} \leq 0.05)$ were showed in values of $E G$ at the $2^{\text {nd }}, 4^{\text {th }}$, and $6^{\text {th }}$ weeks in comparison with the values of $N C G$, and significant increases $(\mathrm{P} \leq 0.05)$ at the $6^{\text {th }}, 8^{\text {th }}$, and $16^{\text {th }}$ weeks when compared to values of $P C G$. Among the results of the $E G$, the highest significant decrease $(\mathrm{P} \leq 0.05)$ in values of IL-10 was reported at the $2^{\text {nd }}$ and $4^{\text {th }}$ weeks (Figure 2).

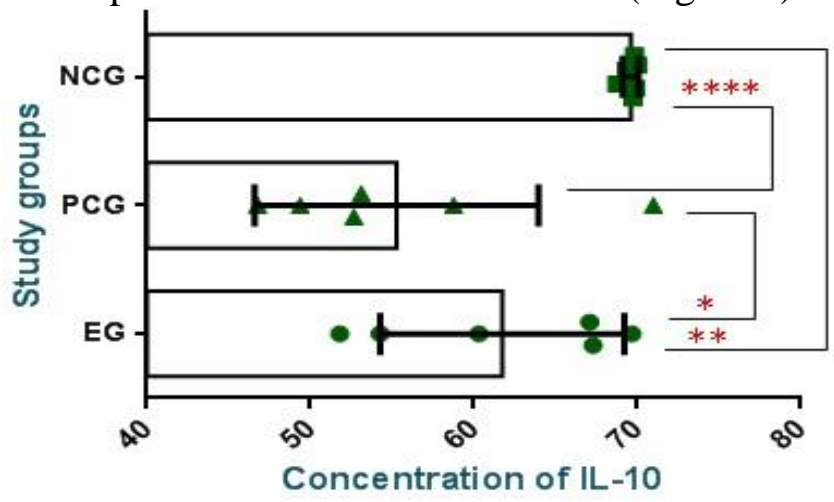

Figure 2. Total results of IL-10 among the experimental groups and the time points $(*),(* *)$, and $(* * * *)$ referred to significant differences between groups as $P \leq \mathbf{0 . 0 5}$, $P \leq 0.01$ and $P<0.0001$ respectively.

Regarding TNF- $\alpha$, insignificant variation $(\mathrm{P} \leq 0.05)$ was detected between the values of the three experimental groups; $E G, P C G$, and $N C G$; at the $1^{\text {st }}$ week. However, significant increases $(\mathrm{P} \leq 0.05)$ were showed in the values of $E G$ at the $2^{\text {nd }}, 4^{\text {th }}$, and $6^{\text {th }}$ weeks in comparison with the values of $N C G$, and significant decreases $(\mathrm{P} \leq 0.05)$ at the $6^{\text {th }}$, $8^{\text {th }}$, and $16^{\text {th }}$ weeks when compared to values of $P C G$. Among the results of the EG, the highest significant increase $(\mathrm{P} \leq 0.05)$ in values of TNF- $\alpha$ was recorded at the $2^{\text {nd }}$ and $4^{\text {th }}$ weeks (Figure 3 ).

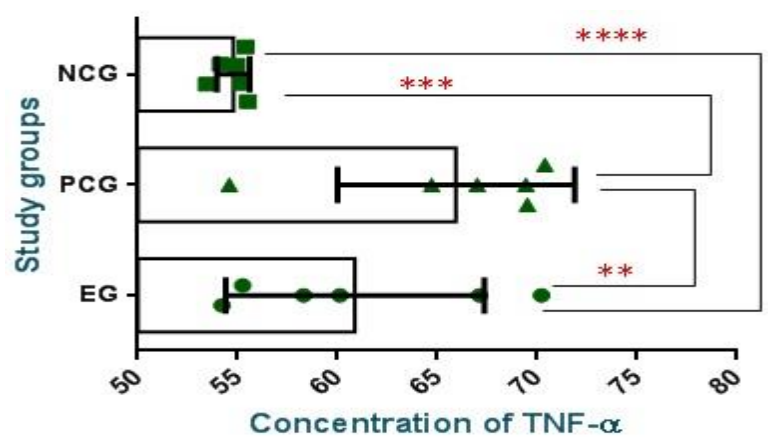

Figure 3. Total results of TNF- $\alpha$ among the experimental groups and the time points. $(* *),(* * *)$, and $(* * * *)$ referred to significant differences between groups as $P \leq 0.01, P<0.001$ and $P<0.0001$ respectively.

Since the $2^{\text {nd }}$ week of this study, immune changes to local SCs transplantation in radial nerve injured 
dogs was revealed a significant increase $(\mathrm{P} \leq 0.05)$ in the levels of IgG and TNF- $\alpha$, and significant decreases $(\mathrm{P} \leq 0.05)$ in IL-10 level. Also, there were notable increases in lymphocytes, and neutrophils at the $2^{\text {nd }}$ week; and in monocytes at the $2^{\text {nd }}$ and $4^{\text {th }}$ weeks. It is well known that traumatic injuries to the nerves induce wellorchestrated cellular and molecular events which lead to the complete disintegration of the nerve segment distal to the lesion site and rapidly fragmented of axon by intrinsic active process of self-destruction (29).

Additionally, evidence indicates an interaction between the nervous system and the immune system in the development of neuropathic pain $(30,31)$. As a result of the absence of the axonal contact, degeneration typically induces a strong neuro-inflammatory response in which the myelinating Schwann cells differentiate into an immature phenotype, start proliferating and help in the degeneration of myelin through triggering pro-inflammatory cytokines within hours (32-34). Moreover, mast cells accumulate in the endoneurium of injured nerves and release mediators that contribute to the recruitment of macrophages and neutrophils, with infiltration of blood-borne monocytes that spread over the entire nerve $(35,36)$.

Rotshenker (2011) mentioned that the time period of myelin removal is determined by the kinetics of macrophage recruitment and the kinetics of the activation of macrophages and Schwann cells to scavenge degenerated myelin (37).

However, phagocytosis is augmented 2 folds and more after degenerated myelin activates the complement system to produce the complement protein (38). Different subtypes of $\mathrm{T}$ cells largely define the character of an immune response.

Upon activation during normal degeneration, Type-1 helper (Th1) cells produce proinflammatory cytokines such as interferon- $\alpha$ (INF$\alpha)$ and tumor necrosis factor- $\alpha$ (TNF- $\alpha$ ) that activate macrophages, neutrophils, and natural killer cells thereby supporting the cellular immune response; while, Type-2 helper (Th2) cells produce anti-inflammatory cytokines such as interleukins (IL-4, IL-5, IL-10, and IL-13) that mediate humoral immunity $(39,40)$.

Eliav et al. (1999) demonstrated that T-cells recruitment to the inflamed nerve in the absence of axonal damage, and to the injured nerves in several models of mononeuropathy (41). Neutrophils respond to tissue injury within minutes by sensing necrotic debris and damageassociated molecular patterns (42). Nadeau et al. (2011) reported that neutrophil accumulation requires IL and TNF receptor signaling, probably TNF- $\alpha$ released from resident cells early after injury (43).

Wang (2018) mentioned that neutrophils also contribute to tissue repair by the release of growth factor, and polarizing phagocytic macro-phages to release anti-inflammatory cytokines cytokines such as IL-10 (42).

Recent evidence from Lindborg et al. (2017) suggests that in the absence of infiltrating monocytes-derived macro-phages, neutrophils can perform a significant phagocytic role in the injured peripheral nerve (44). Davies et al. (2020) recorded that the immune response to peripheral NI is simultane-ously capable of directing resolution of the injury in parts through the pathways of cellular cytotoxicity, and it is a major driver of maladaptive pain (45).

However, Eberl et al. (2015) revealed that the inability to assign function from cell numbers alone is likely due to positive and negative effectors' functions and diver cell subsets (46).

The findings of hematological measurement in this study showed that there were significant differences $(\mathrm{P} \leq 0.05)$ in the levels of $\mathrm{WBC}$ and RBC parameters among all experimental groups; $E G, P C G$, and NCG. Concerning to total WBCs, there insignificant variation $(\mathrm{P} \leq 0.05)$ was detected between the values of the three study groups; $E G$, $P C G$, and NCG; at the $1^{\text {st }}$ week. However, there was significant elevation $(\mathrm{P} \leq 0.05)$ in the values of $E G$ from the $2^{\text {nd }}$ week onward until the last week ( $16^{\text {th }}$ week) when compared to the values of $N C G$, and significant decreases $(\mathrm{P} \leq 0.05)$ from the $4^{\text {th }}$ week onward until the last week $\left(16^{\text {th }}\right.$ week) in comparison to values of $P C G$. Among results of $E G$, the highest significant increases $(\mathrm{P} \leq 0.05)$ in values of total WBCs were detected at the $2^{\text {nd }}$ week (Figure 4).

In lymphocytes, there was insignificant variation $(\mathrm{P} \leq 0.05)$ detected between the values of the three experimental groups; $E G, P C G$, and $N C G$; at the $1^{\text {st }}$ week. However, there were significant increases $(\mathrm{P} \leq 0.05)$ shown in the values of $E G$ at the $2^{\text {nd }}$ week in comparison to the values of $N C G$, 
and significant decreases $(\mathrm{P} \leq 0.05)$ from the $2^{\text {nd }}$ weeks onward until the last study week $\left(16^{\text {th }}\right.$ week) when compared to values of $P C G$.

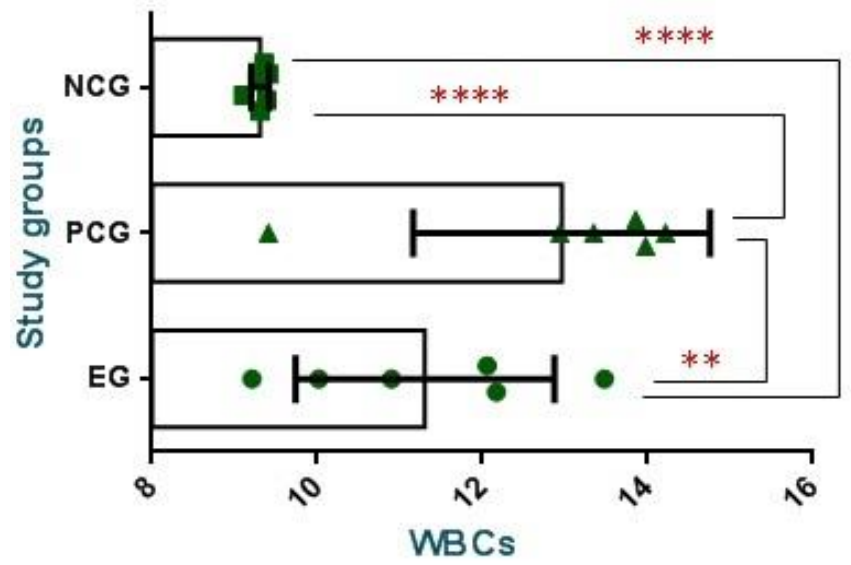

Figure 4. Total results of total WBCs among the experimental groups and the time points. (**) and (****) referred to significant differences between groups as $P \leq 0.01$ and $P<0.0001$ respectively

Among results of $E G$, the highest significant increases $(\mathrm{P} \leq 0.05)$ in values of lymphocytes were recorded at the $2^{\text {nd }}, 4^{\text {th }}$, and $6^{\text {th }}$ weeks (Figure 5).

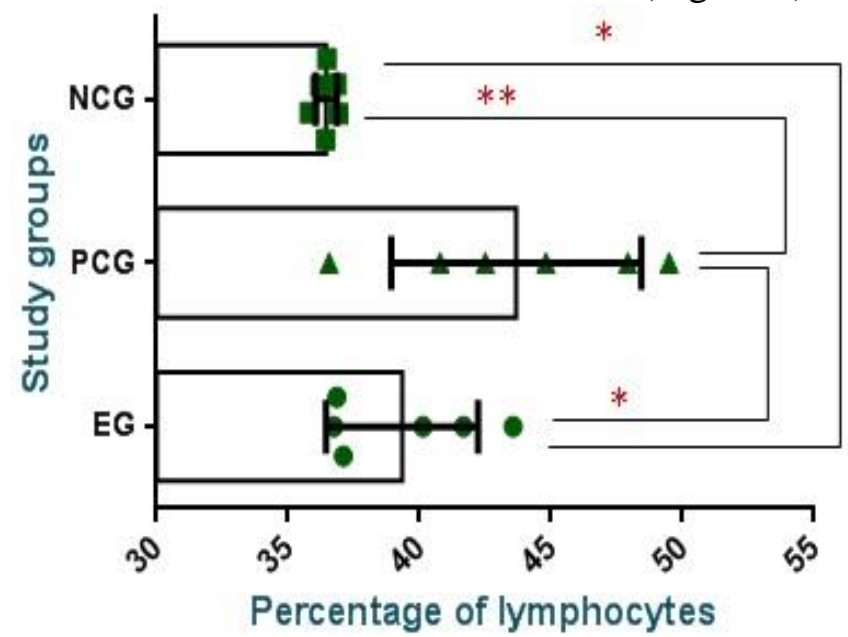

Figure 5. Total results of lymphocytes among the experimental groups and the time points. (*) and (**) referred to significant differences between groups as $\mathbf{P} \leq 0.05$ and $\mathbf{P}<0.01$ respectively.

No significant differences $(\mathrm{P} \leq 0.05)$ in levels of neutrophils were seen between the values of the three experimental groups; EG, PCG, and NCG; at the 1 st week. However, there were significant decreases $(P \leq 0.05)$ shown in values of $E G$ at the 2nd and 4th weeks in comparison to the values of $\mathrm{NCG}$, and significant increases $(\mathrm{P} \leq 0.05)$ at the 2nd week when compared to values of PCG. Among the results of EG, insignificant differences $(\mathrm{P} \leq 0.05)$ in values of neutrophils were reported among all the study time points except for the 2 nd week which showed a significant reduction $(\mathrm{P} \leq 0.05)$ in its values (Figure 6).

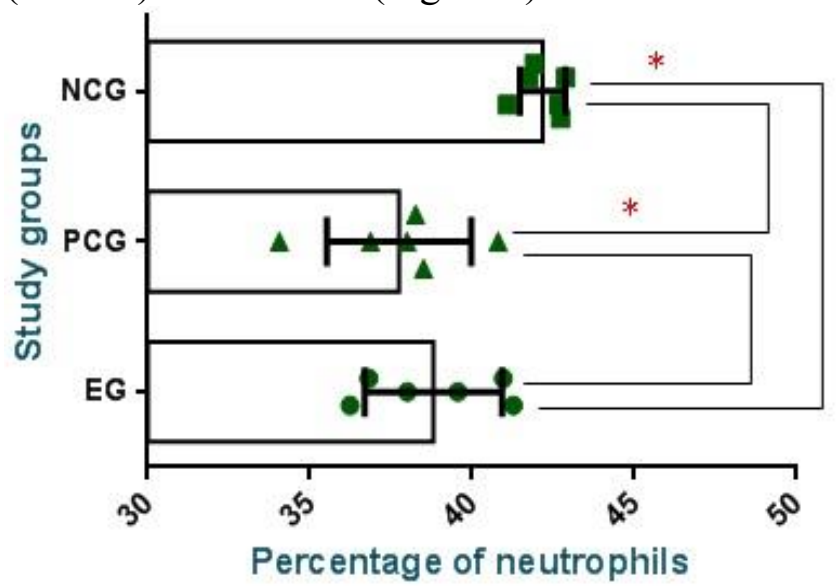

Figure 6. Total results of neutrophils among the experimental groups and the time points. (*) referred to significant differences between groups as $\mathbf{P} \leq \mathbf{0 . 0 5}$.

Regarding the monocytes, there were significant increases $(\mathrm{P} \leq 0.05)$ shown in the values of $E G$ at the $2^{\text {nd }}$ and $4^{\text {th }}$ weeks in comparison to the values of $N C G$, and significant decreases $(\mathrm{P} \leq 0.05)$ in values of all the study time points except for the $2^{\text {nd }}$ week that showed insignificant differences $(\mathrm{P} \leq 0.05)$ when compared to values of $P C G$. Among the results of $E G$, the highest significant increases $(\mathrm{P} \leq 0.05)$ in the values of monocytes were recorded at the $2^{\text {nd }}$ and $4^{\text {th }}$ weeks (Figure 7).

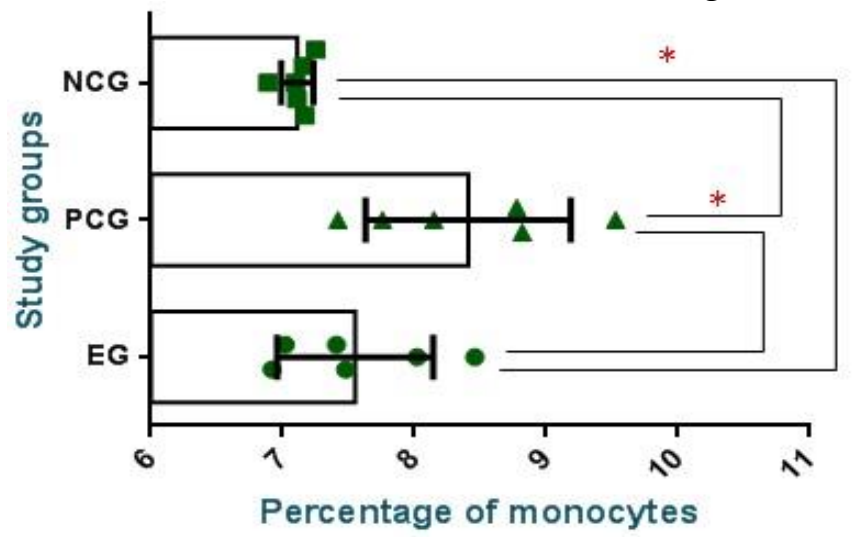

Figure 7. Total results of monocytes among the experimental groups and the time points. (*) referred to significant differences between groups as $\mathbf{P} \leq \mathbf{0 . 0 5}$.

For total RBCs, insignificant variation $(\mathrm{P} \leq 0.05)$ was observed between the values of the three experimental groups; EG, PCG, and NCG; at the 1 st week. However, significant increases $(\mathrm{P} \leq 0.05)$ were showed in values of EG at the 8th and 16th weeks in comparison to the values of NCG, and significant increases $(\mathrm{P} \leq 0.05)$ from the 2 nd week towards the last week (16th week) when compared to the values of PCG. Among the results of EG, 
the highest significant increases $(\mathrm{P} \leq 0.05)$ in values of RBCs were recorded at the 8th and 16th weeks (Figure 8).

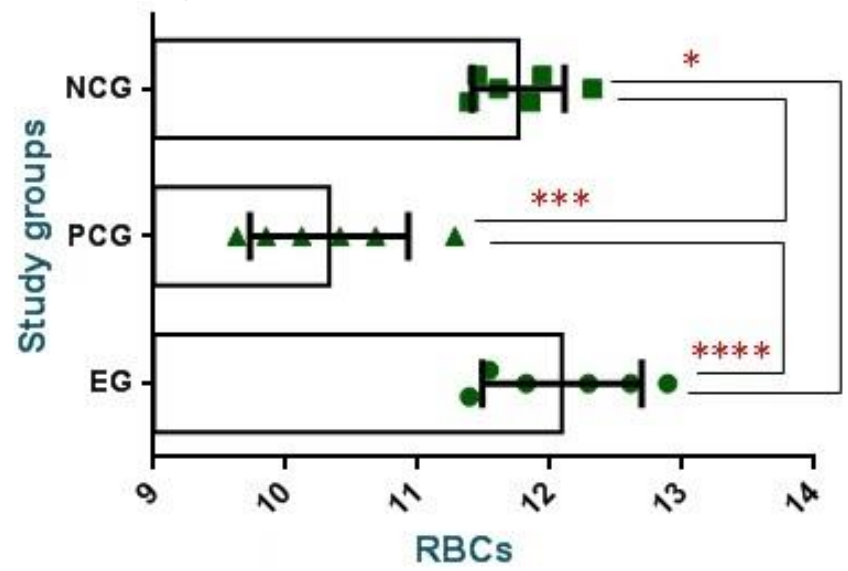

Figure 8. Total results of total RBCs among groups of dogs and the time points. $(*),(* * *)$, and $(* * * *)$ referred to significant differences between groups as $\mathbf{P} \leq \mathbf{0 . 0 5}$, $P \leq 0.001$, and $P<0.0001$ respectively.

Regarding the PCV, there were insignificant differences $(\mathrm{P} \leq 0.05)$ between the values of the three experimental groups; $E G, P C G$, and $N C G$; at all-time points of the study as well as among the values of $E G$ (Figure 9).

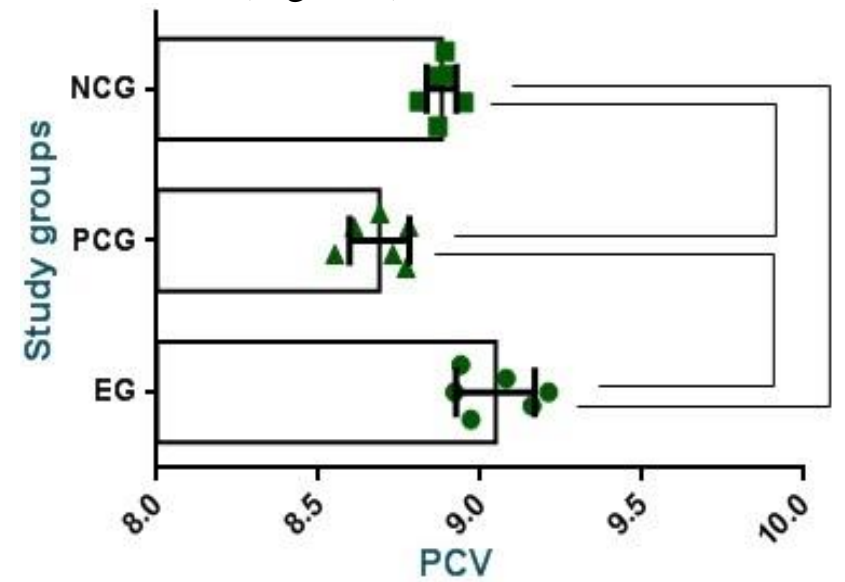

Figure 9. Total results of $\mathrm{PCV}$ among the experimental groups and the time points.

For the $\mathrm{Hb}$ concentration, insignificant variation $(\mathrm{P} \leq 0.05)$ was observed between the values of three study groups; $E G, P C G$, and $N C G$; at alltime points of the study. Among values of $E G$, the highest significant increases $(\mathrm{P} \leq 0.05)$ in values of RBCs were recorded at the $4^{\text {th }}, 6^{\text {th }}, 8^{\text {th }}$ and $16^{\text {th }}$ weeks (Figure 10).

In this study, the values of total RBCs were showed significant increases particularly in the final week of the study. This might be attributed to the facts that experimental animals did not undergo extensive bleeding/hemorrhage during surgical transaction of radial nerves, and to that all animals received a high post-operative environmental and nutritional cares.

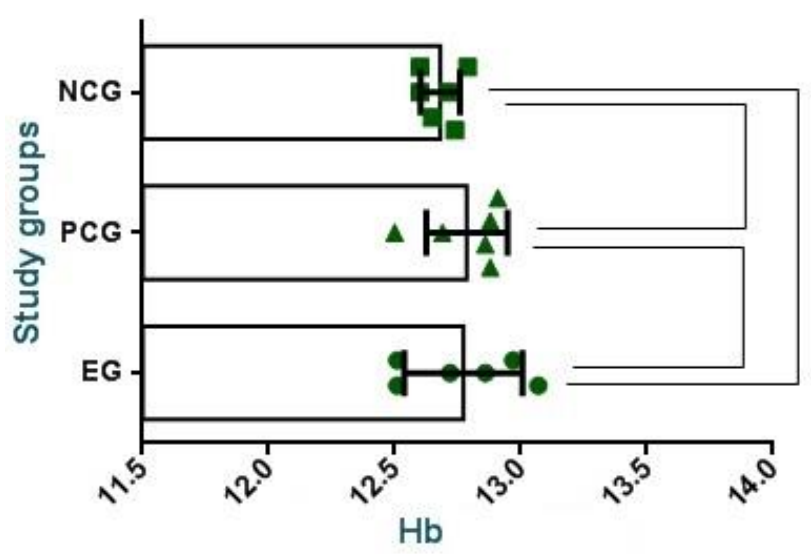

These conditions could participate actively in the improvement of hematological parameters. Besides the placenta that is considered an important and useful source for human derived extracellular matrix for tissue engineering, could have an enhancement role for production of new RBCs (18). Matrix-derived umbilical cord can act as a niche for mesenchymal cells because it contains abundant growth factors and extracellular protein which clearly provide a suitable environment for SCs and mature cells adherence and growth (47). Miharada and Nakamura (2012) reported that the hematopoietic SCs present in bone marrow and umbilical cord are promising materials for in vitro production of $\mathrm{RBCs}$, as well as providing a useful resource without any further complicated critical concerns (48). Ivanović and Vlaski (2012) concluded that the cord blood contains a heterogeneous population of SCs and progenitor, in addition to transplantation these cells could be used also for ex vivo production of mature cells as RBCs (49). Esposito (2018) highlighted that SCs represent an interesting alternative to blood transfusion as they could ensure adequate supplies of RBCs of a particular blood group and reduce some of the risks associated with blood transfusion such as infections (50).

\section{Conclusions}

Although the data of our study indicated the superiority of HUC-MSCs and SSCs in restoring of radial nerve function without muscle atrophy and movement dysfunction, methodology for isolation and proliferation of SCs and for their 
direction to specific lineages to replace neurons has moved at an extraordinary pace, and the promise of SCs as therapeutic agents in neural repair remains enormous. There is a critical role which might have been played by the immune system; therefore, further studies to detect function and/or dysfunction of cellular and humoral immune response during acute and chronic forms of peripheral neuropathies, as well as the role other complements in improving healing of injured nerves should be aimed. Also, we suggested that HUC-MSCs and SSCs may act as an alternative and permanent secondary supporting source of RBCs production. This point makes the utilized SCs a strong tool for tissue engineering.

\section{Authors' contributions}

Haidar H.E. Al-Magsoosi was responsible for the collection of blood samples, data collection, and immune-hematological testing; Assist-Prof. Dr. Huda S.J. Al-Bayati was responsible for the preparation of HUC-MSCs; and Prof. Dr. Hameed A.K. Al-Tememe was responsible for the surgical procedure of NI and implantation of HUC-MSCs therapy. All authors contributed in writing this manuscript and have read and approved the final version.

\section{Acknowledgment}

The authors would like to acknowledgment the Department of Microbiology and Department of Surgery and Obstetrics, College of Veterinary Medicine, University of Baghdad, Baghdad / Iraq, for providing the necessary facilities for this study.

\section{Conflict of interest}

There are no competing financial and nonfinancial interests.

\section{References}

1. Kieseier BC, Lehmann HC, zu Hörste GM. Autoimmune diseases of the peripheral nervous system. Autoimm Rev. 2012; 11(3):191-5.

2. Obrosova IG. Diabetes and the peripheral nerve. Biochim Biophys Acta Mol Basis Dis. 2009; 1792 (10): 931-40.

3. Eser F, Aktekin LA, Bodur H, Atan C. Etiological factors of traumatic peripheral nerve injuries. Neurol India. 2009; 57 (4): 434-7.

4. Gupta G, Mammis A, Maniker A. Malignant peripheral nerve sheath tumors. Neurosurg Clin N Am. 2008; 19 (4):533-43.

5. Klusáková I, Dubový P. Experimental models of peripheral neuropathic pain based on traumatic nerve injuries - an anatomical perspective. Ann Anat. 2009; 191 (3): 248-59.

6. Isaacs J. Treatment of acute peripheral nerve injuries: current concepts. J Hand Surg. 2010; 35 (3): 491-7.

7. Grinsell D, Keating CP. Peripheral nerve reconstruction after injury: a review of clinical and experimental therapies. BioMed Res Int. 2014; 25: 4 (2014): 1-13.

8. Bingham JR, Kniery KR, Jorstad NL, Horkayne-Szakaly I, Hoffer ZS, Salgar SK. "Stem cell therapy to promote limb function recovery in peripheral nerve damage in a rat model"-Experimental research. Ann Med Surg. 2019; 41: 20-8.

9. Li H, Shen S, Fu H, Wang Z, Li X, Sui X, et al. Immunomodulatory functions of mesenchymal stem cells in tissue engineering. Stem Cell Int. 2019; 1:1 (2019): 1-3.

10. Dadon-Nachum M, Melamed E, Offen D. Stem cells treatment for sciatic nerve injury. Expert Opin Biol Ther. 2011; 11 (12): 15917.

11. Mao AS, Mooney DJ. Regenerative medicine: current therapies and future directions. Proc Natl Acad Sci. 2015; 112 (47): 14452-9.

12. Sundelacruz S, Kaplan DL. Stem cell-and scaffold-based tissue engineering approaches to osteochondral regenerative medicine. In Seminars in cell and developmental biology 2009 Aug 1. Acad Press. 2009; 20 (6): 64655.

13. Lo Sicco C, Tasso R. Harnessing endogenous cellular mechanisms for bone repair. Front Bioen Biotechnol. 2017; 5: 52-8.

14. Kitada M. Mesenchymal cell populations: development of the induction systems for Schwann cells and neuronal cells and finding the unique stem cell population. Anat Sci Int. 2012; 87(1): 24-44.

15. Sengupta D, Waldman SD, Li S. From in vitro to in situ tissue engineering. Ann Biomed Eng. 2014; 42 (7): 1537-45. 
16. Dzobo K, Thomford NE, Senthebane DA, Shipanga H, Rowe A, Dandara C, et al. Advances in regenerative medicine and tissue engineering: Innovation and transformation of medicine. Stem Cell Int. 2018; 25 (2): 1-24.

17. Xue G, He M, Zhao J, Chen Y, Tian Y, Zhao $\mathrm{B}$, et al. Intravenous umbilical cord mesenchymal stem cell infusion for the treatment of combined malnutrition nonunion of the humerus and radial nerve injury. Regen Med. 2011; 6 (6): 733-41.

18. Dan P, Velot É, Mesure B, Groshenry G, Bacharouche $J$, Decot V, et al. Human umbilical cord derived matrix: A scaffold suitable for tissue engineering application. Bio-Med Mat Eng. 2017; 28 (1): 95-100.

19. Wassmuth AK, Riond B, Hofmann-Lehmann R, Lutz $H$. Evaluation of the Mythic 18 hematology analyzer for use with canine, feline, and equine samples. J Vet Diagn Invest. 2011; 23 (3): 436-53.

20. Kassambara A. Practical guide to cluster analysis in R: Unsupervised machine learning. STHDA; 2017; 1 (2017): 17-22.

21. Huebsch N, Mooney DJ. Inspiration and application in the evolution of biomaterials. Nat. 2009; 462 (7272): 426-32.

22. Lutolf MP, Hubbell JA. Synthetic biomaterials as instructive extracellular microenvironments for morphogenesis in tissue engineering. Nat Biotechnol. 2005; 23(1): 47-55.

23. Rajan N, Habermehl J, Coté MF, Doillon CJ, Mantovani D. Preparation of ready-to-use, storable and reconstituted type I collagen from rat tail tendon for tissue engineering applications. Nat Protoc. 2006; 1(6): 2753-61.

24. Al-Asadi RN. A comparative study of using Kessler Suture Pattern versus Polypropylene meshes implantation to repair Tenotomized Achilles tendon in bucks. The Iraqi $\mathrm{J}$ Vet Med. 2018; 42(1):65-71.

25. Al-Hyani OH, Al-Hasan AM. A comparative Study of two techniques for repairing of tracheal defect in dogs. The Iraqi J Vet Med 2019; 43 (1):1-0.

26. Moore MC, Pandolfi V, McFetridge PS. Novel human-derived extracellular matrix induces in vitro and in vivo vascularization and inhibits fibrosis. Bio Mater. 2015; 49:3746.
27. McKay R. Stem cells in the central nervous system. Sci. 1997; 276 (5309):66-71.

28. Yan CX, An YH, Li JH. Research on repairing facial nerve injury of rabbits by neural stem cells and autologous fasia. Chin J Rehabil Theory Pract. 2004; 10(1):21-2.

29. Ydens E, Cauwels A, Asselbergh B, Goethals $\mathrm{S}$, Peeraer L, Lornet $\mathrm{G}$, et al. Acute injury in the peripheral nervous system triggers an alternative macrophage response. J Neuroinflamm. 2012; 9 (1): 1-7.

30. Lawrence DA, Kim D. Central/peripheral nervous system and immune responses. Toxicol. 2000; 142 (3): 189-201.

31. Manley K, Han W, Zelin G, Lawrence DA. Crosstalk between the immune, endocrine, and nervous systems in immunotoxicology. Curr Opin Toxicol. 2018; 10:37-45.

32. Taskinen HS, Olsson T, Bucht A, Khademi M, Svelander L, Röyttä M. Peripheral nerve injury induces endoneurial expression of IFN$\gamma$, IL-10 and TNF- $\alpha$ mRNA. J Neuroimmunol. 2000; 102 (1): 17-25.

33. Shamash S, Reichert F, Rotshenker S. The cytokine network of Wallerian degeneration: tumor necrosis factor- $\alpha$, interleukin- $1 \alpha$, and interleukin-1 $\beta$. J Neurosci. 2002; 22 (8): 3052-60.

34. Saxena S, Caroni P. Mechanisms of axon degeneration: from development to disease. Prog Neurobiol. 2007; 83(3): 174-91.

35. Zuo Y, Perkins NM, Tracey DJ, Geczy CL. Inflammation and hyperalgesia induced by nerve injury in the rat: a key role of mast cells. Pain. 2003; 105(3): 467-79.

36. Perrin FE, Lacroix S, Avilés-Trigueros $M$, David S. Involvement of monocyte chemoattractant protein-1, macrophage inflammatory protein- $1 \alpha$ and interleukin- $1 \beta$ in Wallerian degeneration. Brain. 2005; 128(4):854-66.

37. Rotshenker S. Wallerian degeneration: the innate-immune response to traumatic nerve injury. J Neuroinflamm. 2011; 8(1):109-23.

38. Cámara-Lemarroy CR, Guzmán-de la Garza FJ, Fernández-Garza NE. Molecular inflammatory mediators in peripheral nerve degeneration and regeneration. Neuroimmunomodulation. 2010; 17 (5): 314-24.

39. Moalem G, Xu K, Yu L. T lymphocytes play a role in neuropathic pain following 
peripheral nerve injury in rats. Neurosci. 2004; 129 (3): 767-77.

40. Austin PJ, Berglund AM, Siu S, Fiore NT, Gerke-Duncan MB, Ollerenshaw SL, et al. Evidence for a distinct neuro-immune signature in rats that develop behavioural disability after nerve injury. J Neuroinflamm. 2015; 12(1): 96-112.

41. Eliav E, Herzberg U, Ruda MA, Bennett GJ. Neuropathic pain from an experimental neuritis of the rat sciatic nerve. Pain. 1999 1; 83(2): 169-82.

42. Wang J. Neutrophils in tissue injury and repair. Cell Tissue Res. 2018; 371(3): 531-9.

43. Nadeau S, Filali M, Zhang J, Kerr BJ, Rivest $S$, Soulet D, et al. Functional recovery after peripheral nerve injury is dependent on the pro-inflammatory cytokines IL-1 $\beta$ and TNF: implications for neuropathic pain. J Neurosci. 2011; 31(35):12533-42.

44. Lindborg JA, Mack M, Zigmond RE. Neutrophils are critical for myelin removal in a peripheral nerve injury model of Wallerian degeneration. J Neurosci. 2017; 37 (43): $10258-77$.
45. Davies AJ, Rinaldi S, Costigan M, Oh SB. Cytotoxic immunity in peripheral nerve injury and pain. Front Neurosci. 2020; 14: 142-62.

46. Eberl G, Colonna M, Di Santo JP, McKenzie AN. Innate lymphoid cells: a new paradigm in immunology. Sci. 2015; 348(6237)1-21.

47. Yang Y, Melzer C, Bucan V, von der Ohe J, Otte A, Hass R. Conditioned umbilical cord tissue provides a natural three-dimensional storage compartment as in vitro stem cell niche for human mesenchymal stroma / stem cells. Stem Cell Res Ther. 2016; 7(1):1-4.

48. Miharada K, Nakamura Y. In vitro production of enucleated red blood cells from hematopoietic stem and progenitor cells. InSomatic Stem Cells 2012. Humana Press, Totowa, NJ.2012; 1(1):505-12.

49. Ivanović $Z$, Vlaski M. Production of hematopoietic cells from umbilical cord blood stem cells for transfusion purposes: Focus on ex vivo generation of red blood cells. Sc Med. 2012; 43(2):99-105.

50. Esposito MT. Blood factory: which stem cells?. BMC Hematol. 2018; 18(1):10-4. 
الاستجابة المناعية والدموية نتيجة الغرس الموضعي للخلايا الجذعية المشتقة من الحبل السري

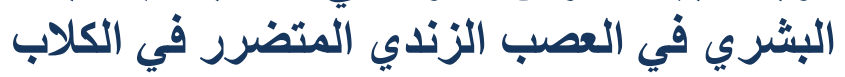

هيدر حسين عيسى 1، هدى سعدون جاسم 2، حميد علي كاظم 3

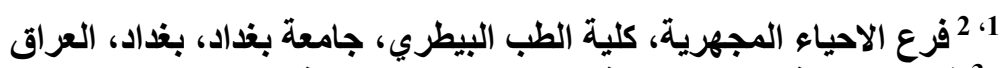

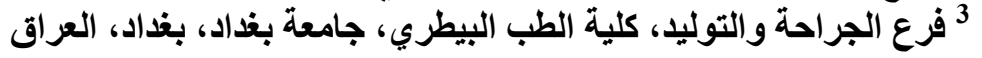

\section{الخلاصة}

اجريت الدراسة الحالية من اجل تقييم التغييرات المناعية والدموية نتيجة الغرس الموضعي للخلايا الجذعية الوسيطة للحبل السري

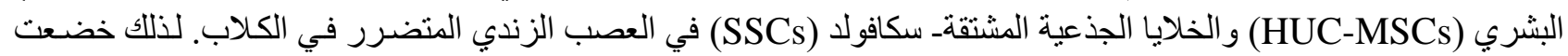

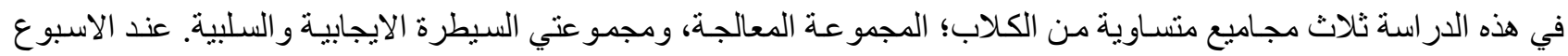

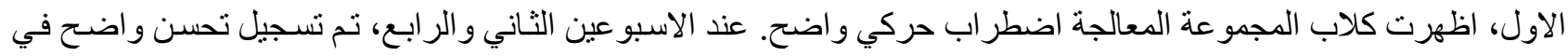

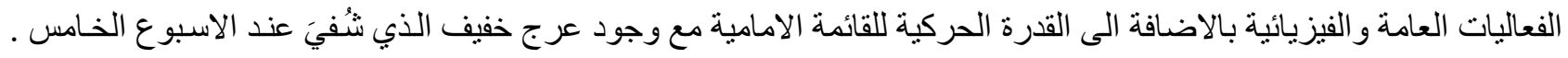

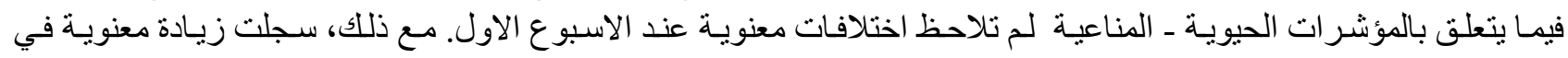

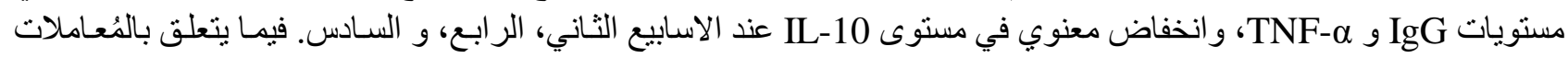

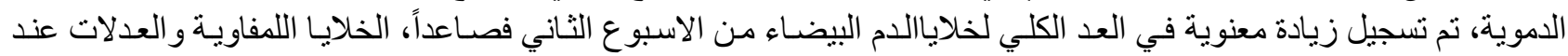

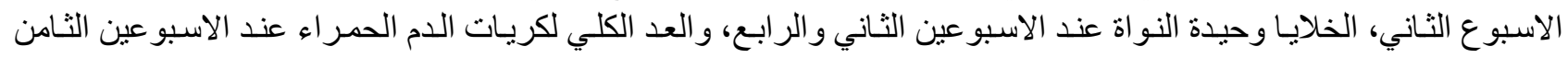

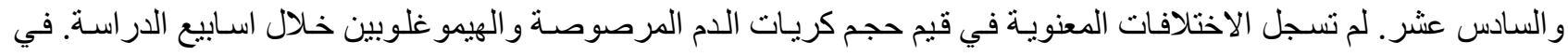

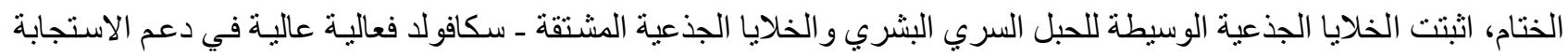

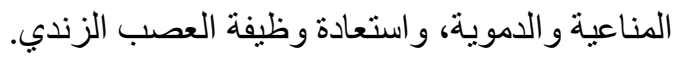
الكلمات المفتاحية: استجابة مناعية، خلايا جذعية، غرس، كلاب، العراق. 